Virginia Commonwealth University VCU Scholars Compass

2010

\title{
Dual mode nanoparticles: CdS coated iron nanoparticles
}

\author{
F. N. Radwan \\ Virginia Commonwealth University \\ K.J. Carroll \\ Virginia Commonwealth University \\ E. E. Carpenter \\ Virginia Commonwealth University, ecarpenter2@vcu.edu
}

Follow this and additional works at: http://scholarscompass.vcu.edu/chem_pubs

Part of the Chemistry Commons

Radwan, F. N., Carroll, K. J., \& Carpenter, E. E. Dual mode nanoparticles: CdS coated iron nanoparticles. Journal of Applied Physics, 107, 09B515 (2010). Copyright (C) 2010 American Institute of Physics.

\section{Downloaded from}

http://scholarscompass.vcu.edu/chem_pubs/28

This Article is brought to you for free and open access by the Dept. of Chemistry at VCU Scholars Compass. It has been accepted for inclusion in Chemistry Publications by an authorized administrator of VCU Scholars Compass. For more information, please contact libcompass@vcu.edu. 


\title{
Dual mode nanoparticles: CdS coated iron nanoparticles
}

\author{
F. N. Radwan, K. J. Carroll, and E. E. Carpenter ${ }^{a)}$ \\ Department of Chemistry, Virginia Commonwealth University, Richmond, Virginia 23284, USA
}

(Presented 20 January 2010; received 31 October 2009; accepted 8 December 2009; published online 5 May 2010)

\begin{abstract}
Reverse micelles can be used in a sequential fashion to make core-shell nanoparticles. Using this technique it is possible to make a magnetic quantum dot, by coating an iron core with a cadmium sulfide shell. Transmission electron microscopy indicated core-shell morphology and narrow size distribution of the obtained particles. Collectively, x-ray powder diffraction and x-ray photoelectron spectroscopy verified the presence of cadmium sulfide on the surface of the nanoparticles. Optical properties of the coated particles were demonstrated using fluorescence spectroscopy. A vibrating sample magnetometer was used to determine magnetic properties. Dual mode cadmium sulfide coated iron core-shell nanoparticles make unique candidates for the use in biomedical applications.

(C) 2010 American Institute of Physics. [doi:10.1063/1.3358079]
\end{abstract}

Fluorescent semiconductor nanoparticles, known as quantum dots (QDs), have attracted attention due to their use in many applications. ${ }^{1}$ For example, QDs can be used as biomarkers in cell labeling and in the detection of biomolecules, ${ }^{2,3}$ in molecular diagnostics, immunoassays, and photodynamic therapies. ${ }^{4-8}$ This is due to their enhanced fluorescence properties and resistance against photobleaching, and their size and composition controlled emission. ${ }^{9,10}$ These distinctive characteristics of QDs make them extraordinary candidates for biomedical applications. In this paper we present $\mathrm{CdS}$ coated iron $(\mathrm{CdS}-\mathrm{Fe})$ core-shell nanoparticles. This combination has the potential of being used as dual mode diagnostic tool.

Both CdS and CdS coated iron nanoparticles were characterized using a number of analytical techniques. X-ray powder diffraction (XRD) was collected using a PANalytical $\mathrm{X}^{\prime}$ pert pro diffractometer at a scanning step of $0.400^{\circ}$, in a $2 \theta$ range from $20^{\circ}$ to $80^{\circ}$ using monochromated $\mathrm{Cu} \mathrm{K} \alpha$ radiation. A JEOL CM120 transmission electron microscope (TEM) fitted with a Gatan digital camera was used to determine the size, dispersion, and morphology of the coated particles. High resolution photoelectron spectra were recorded using an ESCALAB 250 spectrometer. The $180^{\circ}$ hemispherical analyzer and monochromated $\mathrm{Al} \mathrm{K} \alpha$ x-ray excitation (Al anode, $12 \mathrm{kV}, 20 \mathrm{~mA}, \mathrm{~h} v=1486.6 \mathrm{eV}$ ) were applied. The instrument was operated with a magnetic lens in the large area XL-mode with a pass energy of $15 \mathrm{eV}$. Binding energies are given relative to the binding energy of $C 1 \mathrm{~s}$ peak $\left(\mathrm{E}_{\mathrm{b}}\right.$ $=384.6 \mathrm{eV}$ ). An $\mathrm{Ar}^{+}$ion flood gun was used for charge compensation. Fluorescence measurements were obtained using Cary eclipsed fluorometer. The light absorption measurements were measured using Hewlett-Packard 8453 photodiode spectrometer. The hysteresis loop measurements were carried out at room temperature on a Lakeshore model 7300 vibrating sample magnetometer (VSM).

\footnotetext{
a) Author to whom correspondence should be addressed. Electronic mail: ecarpenter2@vcu.edu.
}

Iron nanoparticles coated with cadmium sulfide shell were synthesized using a modified reverse micelles method. ${ }^{11,12}$ Briefly, three micelle systems were mixed under nitrogen, each system contained $0.110 \mathrm{M}$ and $0.331 \mathrm{M}$ of nonylphenoxy poly(ethyleneoxy)ethanols (NP5) for a chain length of five and (NP9) for a chain length of nine receptively in cyclohexane. To the first solution, aqueous of $0.138 M \mathrm{FeCl}_{2} \cdot 4 \mathrm{H}_{2} \mathrm{O}$ was added, and reverse micelles were formed. Once a transparent green micelle solution was obtained, $0.184 \mathrm{~g}$ of solid $\mathrm{NaBH}_{4}$ was added to reduce the metal precursor. Almost instantaneously, the reaction mixture turned black due to the formation of metallic iron. ${ }^{11}$ The magnetic nanoparticles act as the core while the other two micelles systems, one containing $0.093 M$ of aqueous cadmium acetate, and the others that contained $0.085 \mathrm{M}$ aqueous sodium sulfide were added in stepwise fashion. The reaction mixture was then left to react for $1 \mathrm{~h}$ before $0.414 \mathrm{ml}$ of thioglycerol was added to functionalize the $\mathrm{CdS}$ shell of iron nanoparticles and left to react overnight. The produced particles were magnetically extracted and washed with pyridine, acetone, and methanol, respectively, and then were dried under vacuum.

Figure 1 presents a diffraction pattern of the CdS coated

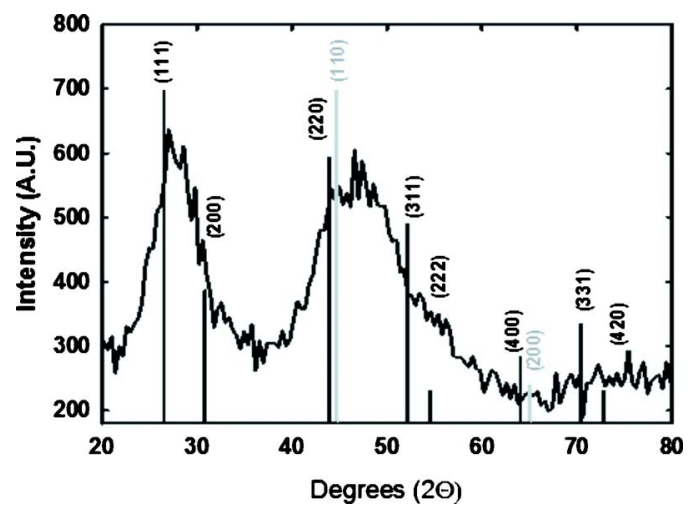

FIG. 1. (Color online) XRD patterns CdS-Fe nanoparticles. The black and gray lines represent JCPDS reference profiles of cadmium sulfide and $\mathrm{Fe}$ Bragg diffraction peak intensities, respectively. 


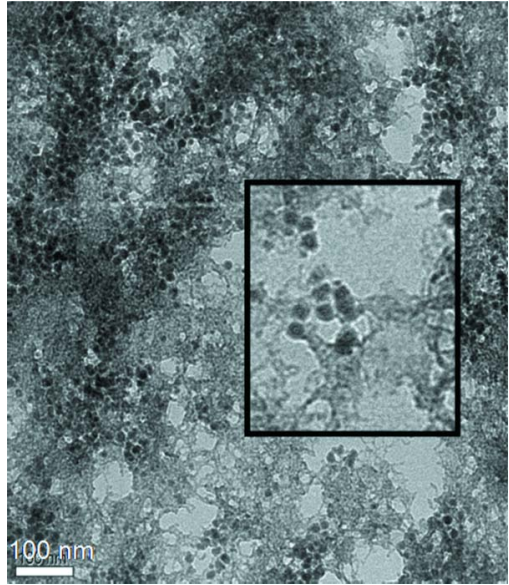

FIG. 2. (Color online) TEM of CdS coated Fe nanoparticles.

nanoparticles. In Fig. 1, the raw data collected are depicted with an overlay of data obtained from JCPDS reference powder diffraction files of cadmium sulfide (Ref. 24) and $\alpha$-Fe (Ref. 25), in which the intensity and position of each diffraction peak are represented by a vertical line. The most intense peaks at $26.5^{\circ}, 30.81^{\circ}, 43.96^{\circ}$, and $52.13^{\circ} 2 \theta$ corresponds to the (111), (200), (311), and (220) planes in the CdS crystal network, respectively. The diffraction pattern shows a broadening of the (110) peak of $\alpha$-Fe and an absence of the 100\% (311) plane of magnetite. From this it can be concluded that the core mainly consists small crystallites of $\alpha$-Fe. The broadening of the $\mathrm{CdS}$ diffraction pattern is due to the small shell thickness size of the coated particles. ${ }^{13}$

As illustrated in Fig. 2 transmission electron microscopy shows monodispersed particles with approximate size of $14 \pm 2.78 \mathrm{~nm}$. Also, the inset of Fig. 2 shows an enlarged portion of the image presents core-shell morphology of these particles that could indicate the iron core and a CdS shell.

Fluorescence and UV-visible absorption measurements of CdS-Fe nanoparticles are presented in Fig. 3. The inset of the figure shows a broad absorbance peak in the wavelength range of 330-460 $\mathrm{nm}$. The coated particles had an emission wavelength of $670 \mathrm{~nm}$ using an excitation wavelength of 335 $\mathrm{nm}$. These results are in agreement with the optical measurements reported in literature of thioglycerol coated $\mathrm{CdS} .{ }^{14}$ Since the absorbance and fluorescence measurements of QDs

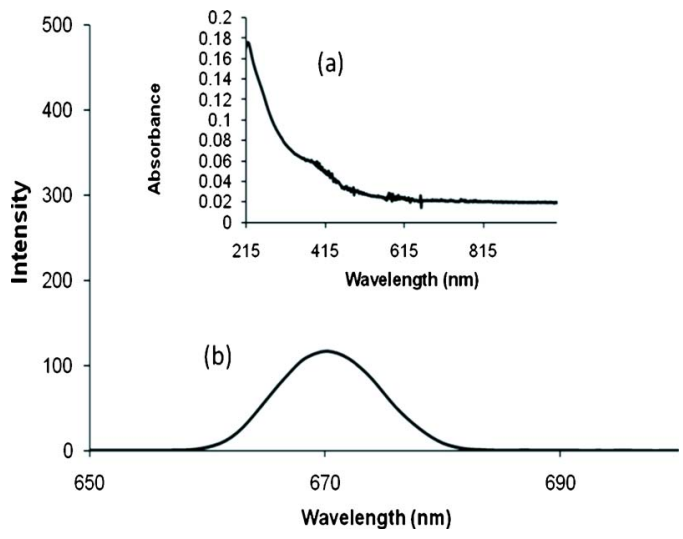

FIG. 3. (Color online) Fluorescence measurements of the CdS-Fe coated particles and UV-visible absorbance data of the coated particles (inset).

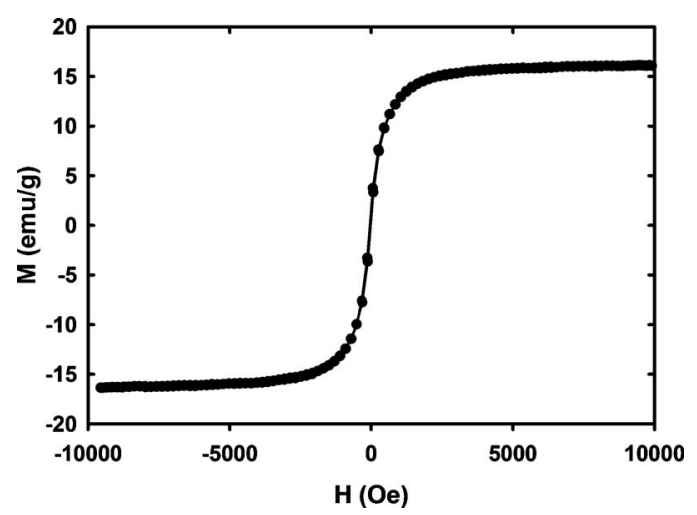

FIG. 4. VSM of CdS coated nanoparticles.

are size dependant, there is broadening in the absorbance and emission spectra resulting from the particles size distribution.

Fluorescence measurements of $\mathrm{CdS}$ by itself had an emission wavelength of $520 \mathrm{~nm}$, whereas the emission wavelength of CdS coated particles is $670 \mathrm{~nm} .^{14}$ This shift in the emission wavelength of the coated particles to a higher wavelength could be due to the interaction of the excitons with a defect that might be present in the lattice of the coated particles or the particle size distribution. ${ }^{15}$

The magnetic properties of the coated particles were also measured at room temperature using VSM. As illustrated in Fig. 4 the particles showed a superparamagnetic behavior with a magnetization of $16 \mathrm{emu} / \mathrm{g}$ and coercivity below 20 Oe. The low magnetization could be mostly due magnetic dilution from the CdS shell and the thioglycerol coating.

To evaluate the surface chemistry of the CdS and $\mathrm{CdS}-\mathrm{Fe}$ nanoparticles, x-ray photoelectron spectroscopy (XPS) measurements have been recorded (see Table I). Survey scans determined that $\mathrm{Na}, \mathrm{S}, \mathrm{O}, \mathrm{Cd}, \mathrm{Cl}$, and, in the case of the CdS-Fe, Fe were on the surface of each sample. The binding energies of the $\mathrm{Cd} 3 \mathrm{~d}_{5 / 2}$ peak for the $\mathrm{CdS}$ and $\mathrm{CdS}-\mathrm{Fe}$ nanoparticles were 405.18 and $405.2 \mathrm{eV}$, which is consistent with literature. ${ }^{16-20}$ An extra peak is shown for the $\mathrm{CdS}-\mathrm{Fe}$ nanoparticles, which is consistent with adsorbed unreacted $\mathrm{CdCl}_{2}$ in the sample. ${ }^{21}$ The $\mathrm{S} 2 \mathrm{p}$ spectra indicate the presence of three peaks at 161.71, 163.84, and $168.98 \mathrm{eV}$. These peaks can be attributed to a cadmium sulfide, thioglycerol, and sodium sulfate, respectively. ${ }^{22,23}$ The sodium sulfate is thought to be an impurity from the sodium sulfide precursor. The Fe $2 p$ spectra indicate the presence of iron(II) on the surface of the CdS-Fe nanoparticles, which can be explained by the adsorption of unreacted $\mathrm{Fe}$ that formed a thin oxide layer. The $\mathrm{O} 1 \mathrm{~s}$ spectra indicated the presence of three peaks

TABLE I. Binding energies for CdS and CdS-Fe nanoparticles synthesized by reverse micelles.

\begin{tabular}{lcc}
\hline \hline & Cd-Fe & CdS \\
\hline Cd 3d & 405.2 and $406.3 \mathrm{eV}$ & $405.18 \mathrm{eV}$ \\
S 2p & $161.60,163.95$, and $169.04 \mathrm{eV}$ & $161.71,163.84$, and $168.98 \mathrm{eV}$ \\
C 1s & $284.57,285.96$, and $287.75 \mathrm{eV}$ & $284.61,285.85$, and $287.44 \mathrm{eV}$ \\
Fe 2p & $711.80 \mathrm{eV}$ & \\
O 1s & $530.34,531.74$, and $533.18 \mathrm{eV}$ & $530.25,530.92$, and $531.80 \mathrm{eV}$
\end{tabular}


at $530.34,531.74$, and $533.18 \mathrm{eV}$. These peaks can be attributed to the presence of two hydroxyl groups from the thioglycerol, water on the surface, and $\mathrm{O}^{2-}$ from sodium sulfate. From carbon 1s spectra it can be concluded that there is the presence of thioglycerol on the surface of the particles. The $\mathrm{C}-\mathrm{C}$ and $\mathrm{C}-\mathrm{O}$ and $\mathrm{C}-\mathrm{S}$ peaks are found at 284.6, 285.96, and $287.75 \mathrm{eV}$, respectively.

In conclusion, magnetic nanoparticles coated with fluorescent cadmium sulfide were synthesized via reverse micelles methods. The CdS-Fe nanoparticles have core-shell morphology as illustrated by transmission electron microscopy. Their combined magnetic and optical properties were illustrated by VSM and fluorescence spectroscopy. They were also functionalized with the organic ligand thioglycerol which enable their dispersion in water. The dual mode diagnostic $\mathrm{CdS}-\mathrm{Fe}$ core-shell nanoparticles are extraordinary candidate to be used as an optical and magnetic marker for biomedical applications.

This research was supported in part by the VCU Nanomaterials Core Characterization Facility, School of Engineering Foundation and by the NSF under Grant No. CHE0820945 MRI (XPS).

${ }^{1}$ Y. P. Sun, B. Zhou, Y. Lin, W. Wang, K. A. S. Fernando, P. Pathak, M. J. Meziani, B. A. Harruff, X. Wang, H. F. Wang, P. J. G. Luo, H. Yang, M. E. Kose, B. L. Chen, L. M. Veca, and S. Y. Xie, J. Am. Chem. Soc. 128, 7756 (2006).

${ }^{2}$ W. J. Parak, T. Pellegrino, and C. Plank, Nanotechnology 16, R9 (2005).

${ }^{3}$ V. P. Pattani, C. F. Li, T. A. Desai, and T. Q. Vu, Biomed. Microdevices
10, 367 (2008).

${ }^{4}$ N. Blow, Nature (London) 456, 825 (2008).

${ }^{5}$ A. Crut, B. Geron-Landre, I. Bonnet, S. Bonneau, P. Desbiolles, and C. Escude, Nucleic Acids Res. 33, e98 (2005).

${ }^{6}$ E. R. Goldman, I. L. Medintz, and H. Mattoussi, Anal. Bioanal. Chem. 384, 560 (2006).

${ }^{7}$ P. Juzenas, W. Chen, Y. P. Sun, M. A. N. Coelho, R. Generalov, N. Generalova, and I. L. Christensen, Adv. Drug Delivery Rev. 60, 1600 (2008).

${ }^{8}$ A. M. Smith, S. Dave, S. M. Nie, L. True, and X. H. Gao, Expert Rev. Mol. Diagn. 6, 231 (2006)

${ }^{9}$ W. L. Shi and X. Y. Ma, Biomed. Mater. Eng. 1, 81 (2006).

${ }^{10}$ A. M. Smith, X. H. Gao, and S. M. Nie, Spectrochim. Acta, Part A 80, 377 (2004).

${ }^{11}$ E. E. Carpenter, S. Calvin, R. M. Stroud, and V. G. Harris, Chem. Mater. 15, 3245 (2003).

${ }^{12}$ A. Merkoçi, S. Marin, M. T. Castaneda, M. Pumera, J. Ros, and S. Alegret, Nanotechnology 17, 2553 (2006).

${ }^{13}$ C. Unni, D. Philip, and K. G. Gopchandran, Spectrochim. Acta, Part A 71, 1402 (2008).

${ }^{14}$ Y. F. Chen and Z. Rosenzweig, Anal. Chem. 74, 5132 (2002).

${ }^{15}$ V. Babentsov and F. Sizov, Opto-Electron. Rev. 16, 208 (2008).

${ }^{16}$ G. Hota, S. B. Idage, and K. C. Khilar, Colloids Surf., A 293, 5 (2007).

${ }^{17}$ R. B. Khomane, A. Manna, A. B. Mandale, and B. D. Kulkarni, Langmuir 18, 8237 (2002).

${ }^{18}$ A. Kumar, A. B. Mandale, and M. Sastry, Langmuir 16, 9299 (2000).

${ }^{19}$ M. Stoev and A. Katerski, J. Mater. Chem. 6, 377 (1996).

${ }^{20}$ M. D. Stoev, J. Touskova, and J. Tousek, Thin Solid Films 299, 67 (1997).

${ }^{21}$ R. D. Seals, R. Alexande, L. T. Taylor, and J. G. Dillard, Inorg. Chem. 12, 2485 (1973).

${ }^{22}$ E. Agostinelli, C. Battistoni, D. Fiorani, and G. Mattogno, J. Phys. Chem. Solids 50, 269 (1989).

${ }^{23}$ M. Volmer, M. Stratmann, and H. Viefhaus, Surf. Interface Anal. 16, 278 (1990).

${ }^{24}$ JCPDS Card No. 10-0454

${ }^{25}$ JCPDS Card No. 87-0721. 